\title{
Quantile Regression Analysis of Wage Inequality in West-African Countries
}

\author{
Ernest Ouédraogo $^{1^{*}}{ }^{\circledR}$, Alou Dembélé ${ }^{\circledR}$, Justin Lwungili Bationo $^{1}$ \\ ${ }^{1}$ Department of Economics and Management, University Thomas Sankara, Burkina Faso \\ ${ }^{2}$ Department of Agricultural Economics, Ankara University, Turkey \\ Email: ernestoued@yahoo.fr
}

Received: 25 June 2021; Revised: 12 October 2021; Accepted: 12 October 2021

\begin{abstract}
In this paper, we investigate the determinants of wage differences in West Africa while dealing with the problem of sample selection in occupational choice. Using data from Household Living Conditions Surveys from six west-African countries, namely Senegal, Mali, Togo, Benin, Burkina Faso and Niger between 2010 and 2018, we estimate Heckman's two-stage model with non-linear quantile regression to assess the effect of individual characteristics on wage rates. After correcting for the sample selection effect, we find that education, experience, marital status, and gender are the major determinants of wage in west-African countries. Subsequently, we apply the Oaxaca decomposition, and the results suggest the presence of wage inequity that is not explained by the observable characteristics between women and men. This gender difference plausibly reflects the persistence of the discrimination against women in the labor market in west-African countries.
\end{abstract}

Keywords: employment, quantile regression, wage, west-Africa

JEL Code: J24, O1, C21

\section{Introduction}

Unlike in developed economies with well-established advanced information technologies, informal and low-paid self-employment in technologically lagging developing countries are a poor but pervasive source of livelihood (Sharker, 2021; King \& Shackleton, 2021; Bassier et al., 2021; ILO, 2019; Amuedo-Dorantes, 2004). These low-paid jobs include own-account workers and contributing family workers. While participation in low-paying jobs affects both men and women, in developing countries certain populations such as women and youth tend to be overrepresented. For example, in 2015, the ILO estimated that the proportion of working women who belong to the category of contributing family workers far exceeded that of men in developing countries: this proportion was 17.9 percentage points higher than that of men in sub-Saharan Africa, with a corresponding figure of 22.9 percentage points in Southern Asia.

With such unequal distribution in employment, inequality of labor income is a major feature of labor markets in Sub-Saharan Africa, where the informal sector accounts for more than 60 percent of the labor force (Diene et al., 2015; Mboup et al., 2016). In order to effectively address poverty, it is essential to effectively identify the factors behind this

Copyright (C2021 Ernest Ouédraogo, et al

DOI: https://doi.org/10.37256/redr.2220211008

This is an open-access article distributed under a CC BY license

(Creative Commons Attribution 4.0 International License)

https://creativecommons.org/licenses/by/4.0/ 
wage inequality. Theoretically, the relation between individual characteristics and wage rates has been established. For instance, conventional wisdom holds that individual might choose their employment to balance work and family life, particularly after the onset of childbearing for women. If true then, individual characteristics such as education need not affect the likelihood that a woman becomes employed; or, to the extent that income from working rises with the level of education, being educated should enhance a woman's chance of participating in paid work, instead of reducing it. However, in developing countries, there is evidence that the overrepresentation of women in unpaid or low-paid work coexists with low educational attainments. For example, in Burkina Faso, evidence from a 2014's multi-sectoral household survey reveals that low-paid self-employed women have only an average 2 years of schooling, as opposed to roughly 7 years for their salaried and wage-earning counterparts. This suggests rather a negative association between the level of education and the likelihood that she is self-employed.

In the literature, the human capital theory emphasizes employee characteristics (education, experience, skills, etc.) as wage determinants. This theory shows that wages and earnings are related to the level of human capital (Becker, 1964). On an empirical level, the analysis of wages is the subject of an important methodological debate, which concerns the validity of the use of regression methods to analyze wage differentials. Since the seminal work of Oaxaca (1973) and Blinder (1973), the decomposition of wage differentials between workers has been widely used to identify and quantify wage differentials and their determinants in the labor market. Studies in the literature have adopted this methodology to highlight the wage gap between domestic and foreign workers and between men and women in subSaharan African countries (Boumahdi \& Giret, 2005; Aeberhardt et al., 2007; Romain et al., 2010; Sall \& Thiaw, 2019; Thiaw, 2020).

However, in sub-Saharan Africa assessing the determinants of these wage rates remains difficult due to the lack of financial registers (Diene et al., 2015; Mboup et al., 2016; Thiaw, 2020, Adair et al., 2012; Belmondo, 2012). The major problem with these empirical studies is the presence of selection bias, as wages are only observed for workers. This implies that people who do not work are not included in these previous studies. However, the sample of workers and non-workers could have different characteristics, which could lead to a biased estimate (Heckman, 1979). Heckman (1974; 1979) developed a parametric method designed to correct for selection bias. Subsequently, other authors like Manski et McFadden (1981); Arbache et al. (2005) introduced a non-parametric estimation which consists of estimating a range of unobservable wages based on the observable characteristics of individuals. Using these methods, Mroz (1987), Buchinsky et al. (2010), Romain et al. (2010) and Sall and Thiaw (2019) found evidence that individual characteristics like marital status and the number of children in the household explained the gender inequality in developing countries. However, none of these previous studies take into account both the existence of sample selection bias and the possible differences in determinants between different wage quantiles across West African countries.

Using the latest data from Household Living Conditions Surveys from six west-African countries, namely Senegal, Mali, Togo, Benin, Burkina Faso and Niger, we estimate Heckman's two-stage model with quantile regression to assess the effect of individual characteristics on wage rates. After correcting for the sample selection effect, we find that education, experience, marital status, and gender are the major determinants of wage in west-African countries. Subsequently, we apply the Oaxaca decomposition (1973) and the results suggest the presence of wage inequity that is not explained the observable characteristics between women and men.

The rest of the paper is structured as follows. Section 2 provides a summary descriptive analysis of the data. Section 3 presents the empirical methodology while Section 4 reports the estimation results. Section 5 discusses the results and provides the overall conclusion and outlook.

\section{Data and descriptive statistics}

The data come from the latest Household Living Conditions Surveys from six sub-Saharan Africa namely Senegal, Mali, Togo, Benin, Burkina Faso and Niger carried between 2010 and 2018. These surveys were carried out by the National Statistics and Demography Agencies with the participation of technical and financial partners alongside the governments, including the World Bank (WB), the World Food Programme (WFP), the Canadian International Development Agency (CIDA) and the United Nations Development Programme (UNDP). These surveys collected information on individuals' characteristics such as employment status, age, gender, marital status. We combined data from these surveys to obtain our final database. We exclude individuals with missing data on our key variables. The final 
sample contains 62,982 individuals, including workers and non-workers. The descriptive statistics on our variables of interest are presented in Table 1.

Table 1. Descriptive statistic

\begin{tabular}{ccccc}
\hline Variables & Mean & Std. Err & Min. & Max. \\
\hline Working & 69.83 & 0.13 & 0 & 1 \\
Not working & 30.77 & 0.13 & 0 & 1 \\
Yearly average wage (FCFA) for workers & 153250 & 22038 & 10855 & 965265 \\
Education level & & & \\
No Education & 0.52 & 0.01 & 0 & 1 \\
Primary & 0.27 & 0.06 & 0 & 1 \\
Secondary or more & 0.20 & 0.08 & 0 & 1 \\
Married & 0.84 & 0.02 & 0 & 1 \\
Age & 33.42 & 6.32 & 15 & 49 \\
Experience & 6.23 & 1.17 & 0 & 28 \\
Household wealth index & & & & 1 \\
Poorer & 0.16 & 0.07 & 0 & 1 \\
Middle & 0.18 & 0.02 & 0 & 1 \\
Richer & 0.21 & 0.04 & 0 & 1 \\
Richest & 0.22 & 0.01 & 0 & 0 \\
Urban resident & 0.74 & 0.19 & 0 & 1 \\
\hline
\end{tabular}

According to the result present in Table 1, these statistics suggest that almost $70 \%$ of individuals are working during the last 12 months. Almost half of the individuals have no education while roughly a quarter have at least a secondary education. $83.9 \%$ are married and age range between 15 and 49 with an average at 33.4 year-old. The average experience is 6.23 years.

\section{Econometric model}

Given the problem of sample selection as earnings are only observed for working individuals, we apply a Heckman model to correct this selection. We rely on two specifications of the Heckman model with quantile regression.

\subsection{Heckman's method}

Recall this paper focus on estimating the average wage of the active population (unemployed and employed), we do not observe the wages of the unemployed and we observe only those of the employed. As wage is not observed for nonworking individuals, it is likely that theses workers present characteristics that are different from workers. Estimating without taking into account this issue might bias the results. This problem is known in econometric modeling as sample selection. Heckman (1974) proposed a method to correct this sample selection bias. This method consists of two steps represented by two equations. 


$$
Y=\left\{\begin{array}{l}
1 \text { if } Y_{i j}^{*}=Z_{i j} \beta+\varepsilon_{i j} \text { (working) } \\
0 \text { if } Y_{i j}^{*}=Z_{i j} \beta+\varepsilon_{i j} \text { (not working) }
\end{array}\right.
$$

Thus, equation 1 presents the employment status of a working individual as salary employees (group A) and selfemployed (group B).

The wage is only known for employees $(Y=1)$ so the regression on the determinants of the wage rate will be as follows:

$$
\omega_{i j}= \begin{cases}X_{i j} \gamma+u_{i j} & \text { si } Y=1 \text { (working) } \\ - & \text { si } Y=1 \text { (not working) }\end{cases}
$$

The correlation between the errors is $\varepsilon_{i j}$ and $u_{i j}$ allowed noted $\alpha$ and the attached normality is postulated to be able to use Heckman's two-step method.

$$
\left(\begin{array}{l}
u_{i j} \\
\varepsilon_{i j}
\end{array}\right) \rightarrow\left(\begin{array}{ll}
\sigma_{1} & \sigma_{12} \\
\sigma_{21} & \sigma_{2}
\end{array}\right)
$$

To consider, the truncation of the wage in the regression to avoid the sample selection bias. The first step in this procedure is to try to identify the sources of differentiation between two populations, in our case, households where the value of the dependent variable (wages) is strictly greater than 0 and households where the value taken by this variable is equal to 0 (those who do not work). Using an Ordinary Least Squares (OLS) model, the first step is to estimate the effects of the different variables of the model on the dependent variable (selection equation) in order to be able to control these same effects when estimating the model (second step).

The conditional mean of the OLS is

$$
\begin{aligned}
E\left[\omega_{i} / y=1\right] & =E\left[\omega_{i} / y^{*} \succ 0\right] \\
& =E\left[X_{i} \gamma+u_{i} / Z_{i} \beta+\varepsilon_{i} \succ 0\right] \\
& =X_{i} \gamma+E\left[u_{i} / Z_{i} \beta+\varepsilon_{i} \succ 0\right] \\
& =X_{i} \gamma+E\left[u_{i} / \varepsilon_{i} \succ-Z_{i} \beta\right]
\end{aligned}
$$

If $\operatorname{Cov}(\varepsilon, u)=\alpha=0$ then $E\left[u_{i} / \varepsilon_{i} \succ-Z_{i} \beta\right]=0$ then there is no sample selection. In contrast, if $\operatorname{Cov}(\varepsilon, u)=\alpha \neq 0$, the conditional mean is $X \lambda$ biased, so the selection effect must be considered.

$$
E\left[u_{i} / \varepsilon_{i} \succ-Z_{i} \beta\right]=\alpha \sigma_{u}\left[\frac{\phi\left(\frac{Z_{i j} \beta}{\sigma_{\varepsilon}}\right)}{\Phi\left(\frac{Z_{i j} \beta}{\sigma_{\varepsilon}}\right)}\right]
$$

Where and $\Phi$ are $\phi$ respectively the distribution function and the density of the normal distribution $N(0,1)$. Thus, the OLS estimate considering the conditional mean is as follows: 


$$
\begin{aligned}
E\left[\frac{\omega_{i}}{y}=1\right] & =X_{i} \gamma+\alpha \sigma_{u}\left[\frac{\phi\left(\frac{Z_{i j} \beta}{\sigma_{\varepsilon}}\right)}{\Phi\left(\frac{Z_{i j} \beta}{\sigma_{\varepsilon}}\right)}\right] \\
& =X_{i} \gamma+\alpha \sigma_{u} \lambda_{i}\left(\alpha_{\varepsilon}\right) \\
& =X_{i} \gamma+\gamma_{\lambda} \lambda_{i}\left(\alpha_{\varepsilon}\right)
\end{aligned}
$$

The vector $\lambda$ is called the inverse of the Mills ratio noted: $\lambda=\frac{f(Z \beta)}{F(Z \beta)}$ with $f$ the density function of the reduced centered normal distribution law and $F$ its distribution function.

The second step thus consists of carrying out an OLS regression on individuals whose variable of interest $\omega$ is observed and integrating the inverse of the Mils ratio $\lambda$. Therefore,

$$
E\left[\frac{\omega_{i}}{y}=1\right]=X_{i} \gamma+\gamma_{\lambda} \lambda_{i}\left(\alpha_{\varepsilon}\right)+v_{i}
$$

In the Heckman's method quantile regression, instead of a mean-conditional regression, equation 7 is estimated with quantile estimation. This estimation allows to account for differences in wage levels. We perform regression on the first, fifth and ninth quantile. Estimates are made for these three quantiles of the conditional distribution of the log

$$
\begin{gathered}
Q_{W_{i}}(\tau / X)=X_{i} \gamma_{\tau}+\alpha_{\tau} \lambda+u_{\tau, i} \text { where } u_{\tau, i} \rightarrow N\left(0, \sigma_{\tau}\right) \\
\text { Decile }_{\tau}[\log [\text { wage } / X]]=X^{\prime} \gamma_{\tau}
\end{gathered}
$$

These quantum regressions allow to observe the effect of the determinants of the wage rate varies for each decile. Graphical representation of each coefficient is also possible using such a non-linear regression. We use the correlation coefficient between the predicted value of the wage rate and the true value to compare these two models. Similarly, we will use standard errors.

\subsection{Decomposition methods}

After having found different methods for estimating the wage rate of the self-employed, we look at the wage gap between men and women on the one hand and the gap according to the level of qualification on the other hand. It often happens that, when we see the difference in average between two groups, we talk about wage discrimination. However, this difference can be explained by the level of competence but by unobservable facts such as discrimination. Thus, since the work on the Blinder-Oaxaca decomposition, this method has been widely used in the labor market. Some, to analyze racial discrimination (USA), others on immigration (France) or on gender discrimination (e.g. Jarrell \& Stanley, 2004; Weichselbaumer \& Winter-Ebmer, 2005).

Suppose we have two groups A and B. The average wage gap is

$$
\Delta \bar{Y}: \Delta \bar{Y}=\Delta \bar{Y}_{A}-\Delta \bar{Y}_{B}
$$

In the context of linear regression, this difference can be broken down into a part explained by the variables and a part not explained. The unexplained part is the part that discriminates between the two groups. For example, the difference in wages between men and women can be broken down into a part that is due to the difference and a part that 
is due to gender.

Expression 10 can be writing as follows:

$$
\Delta \bar{Y}=\bar{X}_{A}^{\prime} \hat{\beta}_{A}-\bar{X}_{B}^{\prime} \beta_{B}
$$

Expression 11 can be reworded as follows:

$$
\Delta \bar{Y}=\underbrace{\left(X_{A}^{\prime}-X_{B}^{\prime}\right)^{\prime} \hat{\beta}_{B}}_{\text {variable differences }}+\underbrace{\bar{X}_{B}^{\prime}\left(\beta_{A}-\beta_{B}\right)}_{\text {differences coefficients }}+\underbrace{\left(X_{A}^{\prime}-X_{B}^{\prime}\right)^{\prime}\left(\beta_{A}-\beta_{B}\right)}_{\text {differences interactions }}
$$

In equation 12, we see that the first term is the difference explained by the level of the variables. The second term is the difference due to the level of the coefficients while the last term is due to the interaction of the two (variable and coefficient). This decomposition can be estimated for each explanatory variable.

More generally, researchers prefer to use the double decomposition of Blinder and Oaxaca, which consists of expressing the difference in an explained variance and an unexplained variance. For this, we use a noted $\beta_{R}$ reference vector. This coefficient vector can be the coefficients in a world with no difference between the two groups. In labor market research, it is the one without discrimination between the groups.

$$
\Delta \bar{Y}=\underbrace{\left(\bar{X}_{A}-\bar{X}_{B}\right)^{\prime} \hat{\beta}_{R}}_{\text {explained by variables }}+\underbrace{\bar{X}_{A}^{\prime}\left(\hat{\beta}_{A}-\hat{\beta}_{B}\right)+\bar{X}_{B}^{\prime}\left(\hat{\beta}_{R}-\hat{\beta}_{B}\right)}_{\text {unexplained }}
$$

Equation 13 divides the difference in the mean between the two groups into a portion that is explained by the difference in the explanatory variables (term 1 ) and a portion that is not explained by the variables (term 2 and term 3 ).

It is also possible to estimate in detail, one estimate of each variable term per variable:

$$
\begin{aligned}
& \left(\bar{X}_{A}-\bar{X}_{B}\right)^{\prime} \hat{\beta}_{R}=\left(\bar{X}_{1 A}-\bar{X}_{1 B}\right)^{\prime} \hat{\beta}_{1 R}+\left(\bar{X}_{2 A}-\bar{X}_{2 B}\right)^{\prime} \hat{\beta}_{2 R}+\cdots \\
& \bar{X}_{A}^{\prime}\left(\hat{\beta}_{A}-\hat{\beta}_{R}\right)=\bar{X}_{1 A}^{\prime}\left(\hat{\beta}_{1 A}-\hat{\beta}_{1 R}\right)+\bar{X}_{2 A}^{\prime}\left(\hat{\beta}_{2 A}-\hat{\beta}_{2 R}\right)+\cdots \\
& \bar{X}_{B}^{\prime}\left(\hat{\beta}_{R}-\hat{\beta}_{B}\right)=\bar{X}_{1 B}^{\prime}\left(\hat{\beta}_{1 R}-\hat{\beta}_{1 B}\right)+\bar{X}_{B}^{\prime}\left(\hat{\beta}_{2 R}-\hat{\beta}_{2 B}\right)+\cdots
\end{aligned}
$$

The choice of the reference coefficients $\beta R$ is left to the discretion of the researcher (Hlavac, 2014).In most labor market studies, assumes that only one group faces discrimination. Thus, a simple solution would be to take the coefficient of one of the groups as the vector of the reference coefficient: $\beta_{R}=\beta_{A}$ or $\beta_{R}=\beta_{B}$. However, other researchers suggest weighting the coefficients of the two groups. For example, Reimers (1983) proposes the same weighting for the two coefficients derived from regressions A and B :

$$
\hat{\beta}_{R}=\frac{\hat{\beta}_{A}+\hat{\beta}_{B}}{2}
$$

Cotton (1988) suggests a weighting in proportion to the size of the group:

$$
\hat{\beta}_{R}=\frac{n_{A}}{n_{A}+n_{B}} \hat{\beta}_{A}+\frac{n_{B}}{n_{A}+n_{B}} \hat{\beta}_{B}
$$


As suggested by Hlavac (2014), we also use a breakpoint based on gender and level of qualification.

\section{Empirical results}

\subsection{Standard heckman linear regression}

The estimation of wage rates might be affected by the difference in sample sizes. Fortunately, our sample is roughly 'balanced'. We estimate the effect of individual characteristics on the log of salary. The explanatory variables are gender, age, experience, an education level (in years), qualification level and branch of activity. The standard Heckman regression result is presented in Table 2 below.

The logit column in Table 2 shows that age does not explain whether an individual is an employee or not. We also find that experience contributes to the discrimination of these two groups. However, the coefficient of experience squared is positive, which seems to indicate a convex shape. This means that the marginal effect of experience on wages declines for the first few years and then increases as one age in employment. Regarding the level of qualification, it appears that qualified people are twice as likely to be employees as entrepreneurs. Indeed, the administration and the formal private companies employ, more generally, qualified people while those who are not qualified are forced to make do with their own small businesses: trade, fields of culture, crafts, etc.

Table 2. Standard Heckman regression. The dependant variable in the first stage is Working (1/0) and the dependant variable in the second stage is log of wage

\begin{tabular}{|c|c|c|c|c|}
\hline & \multicolumn{2}{|c|}{ First stage } & \multicolumn{2}{|c|}{ Second-stage } \\
\hline & $\mathrm{dy} / \mathrm{dx}$ & pvalue & $\mathrm{dy} / \mathrm{dx}$ & pvalue \\
\hline Age & 0.002 & 0.22 & 0.008 & $0.008 * * *$ \\
\hline Experience & 0.64 & $0.000 * * *$ & -0.50 & $0.000 * * *$ \\
\hline experience sqaure & 0.06 & $0.000 * * *$ & 0.05 & $0.000 * * *$ \\
\hline Level of education & 0.02 & $0.004 * * *$ & 0.04 & $0.000 * * *$ \\
\hline \multicolumn{5}{|c|}{ Marital status: Ref. single } \\
\hline Monogame & -0.14 & $0.01 *$ & 0.38 & $0.025 * *$ \\
\hline Polygamist & -0.19 & $0.004 * * *$ & 0.251 & $0.012 * * *$ \\
\hline \multicolumn{5}{|c|}{ Qualification : ref. unqualified } \\
\hline Qualified & 0.68 & 0.000 & 0.18 & 0.42 \\
\hline \multicolumn{5}{|l|}{ Sex: female ref. } \\
\hline Man & 0.42 & $0.002 * * *$ & 0.56 & $0.005 * *$ \\
\hline \multicolumn{5}{|l|}{ Branches: ref. Industry } \\
\hline Primary & -0.61 & $0.000 * * *$ & -0.11 & $0.047 * *$ \\
\hline Services & 0.18 & 0.15 & 0.057 & $0.098^{*}$ \\
\hline \multicolumn{5}{|l|}{ Inverse of the Mils ratio } \\
\hline MRI & 1.72 & $0.040^{* *}$ & 2.04 & $0.061 *$ \\
\hline Constant & & & 6.44 & $0.000 * * *$ \\
\hline Observations & 62,982 & & 62,982 & \\
\hline
\end{tabular}


Regarding socio-demographic variables, men are $12 \%$ more likely than women to be employed. Indeed, women own a large proportion of the small businesses operating in the informal sector. Since they do not have access to the financial market, they organize tontines to finance their small businesses. As for the marital situation, we had three groups: single people, monogamous married people, and polygamous married people. Being married (monogamous or polygamous) reduces the chance of being employed, i.e. the married are more likely to be entrepreneurs.

The equation for estimating the wage rate was estimated only on group A (employees) in Heckman's second equation, which we have assumed here to be linear (OLS). In this second step, the Mils ratio is added to this list of repressors. The coefficient related to the Mils ratio is significantly equal to zero. Therefore, the correlation between the two error terms is zero $(\alpha=0)$. This result suggests that there is no selection bias. Therefore, the OLS coefficients derived only from the regression on group A allow the estimation of the wage of group B without any prior correction.

In this case, only age, experience and level of education are found to have coefficients significantly different from zero at the $5 \%$ threshold. It appears that the wage rate decreases with minimum experience to a threshold with increasing experience. This seems to be explained as a negative sign in front of experience squared. As for gender, we can see that men's wages are 7\% higher than those of women. However, this gap could not be due solely to gender discrimination (Blinder, 1973; Oaxaca, 1973; Romain et al., 2010).

As the coefficient of the inverse of the Mils ratio is not significant at the $5 \%$ threshold, we will explore and see if the coefficients are different according to the wage level. We will be able to attempt this with quantile regression.

\subsection{Heckman method with quantile regression}

The results of the second stage of the Heckman regression are presented in Table 3. It appears that on the three regressions (low, median, and high pay), the coefficient of the inverse of the Mils Ratio is not significant at the 5\% threshold. However, the regression based on the fifth decile indicates the presence of selection bias at the $10 \%$ threshold.

Table 3. Quantitative Heckman regression (Second stage results)

\begin{tabular}{|c|c|c|c|c|c|c|}
\hline & decile 1 & & decile 5 & & decile 9 & \\
\hline Variables & Coef & pvalue & Coef & pvalue & Coef & pvalue \\
\hline age & 0.006 & 0.07 & 0.009 & $0.06^{*}$ & 0.01 & 0.6 \\
\hline experience & 0.40 & $0.000 * * *$ & 0.53 & $0.000 * * *$ & 0.38 & $0.005 * * *$ \\
\hline experience carr'e & 0.03 & $0.002 * * *$ & 0.05 & $0.000 * * *$ & 0.03 & $0.02 * *$ \\
\hline Level education of & 0.045 & $0.000 * * *$ & 0.04 & $0.00 * * *$ & 0.02 & $0.05^{*}$ \\
\hline \multicolumn{7}{|c|}{ Qualification: ref. no quality } \\
\hline Qualifies & 0.15 & $0.005 * * *$ & 0.57 & $0.03 * *$ & 0.17 & $0.002 * * *$ \\
\hline \multicolumn{7}{|l|}{ Sex: ref. female } \\
\hline Man & 0.001 & 0.98 & 0.04 & 0.58 & 0.14 & 0.31 \\
\hline \multicolumn{7}{|l|}{ Ref Industry } \\
\hline Primary & -0.33 & 0.12 & -0.25 & 0.41 & 0.11 & 0.80 \\
\hline Services & -0.16 & $0.019 * *$ & -0.04 & $0.011^{* *}$ & 0.52 & $0.000 * * *$ \\
\hline \multicolumn{7}{|l|}{ Inverse of the Mils ratio } \\
\hline MRI & 1.30 & $0.007 * * *$ & 0.77 & $0.023 * *$ & 0.36 & $0.038 * *$ \\
\hline Constant & 5.85 & $0.000 * * *$ & 5.57 & $0.00 * * *$ & 7.73 & $0.000 * * *$ \\
\hline Observations & 52,982 & & 52,982 & & 52,982 & \\
\hline
\end{tabular}


Using the ANOVA test to compare the different coefficients between the three quantiles, it appears that there is no significant difference between the three quantiles. This result is valid at the individual and global level.

By performing a quantile regression on the different quantile, we obtain the graph of marginal effects with the $95 \%$ confidence interval (shaded area). If the marginal effect is within the confidence interval of the OLS then the difference between the OLS and the quantile for this decile is not as significant. We will try to explain whether the OLS coefficient was under-or overestimated.

For interpretation, the constant corresponds to the effect of persons with the reference modalities in the regression. For our case, it is the decile of salaried workers with women without experience, less old, without qualifications, working in the agricultural sector (primary in general). For these individuals, the log wage rate is 5.68 for the first decile and we pass to 6.13 for the median before reaching 7.60 for the last decile. While the OLS regression predicted this effect to be 6.43. Therefore, the OLS underestimates for the first 5 quantiles and underestimates for the rest.

The inverse of the Mils ratio is overestimated by the OLS for the last two quantiles, otherwise, it is underestimated for all other quantiles. It is significant for the first three quantiles. This gives a hint of selection for this group.

The regression also shows that the effect of age on the wage rate was significantly underestimated for high earners. In fact, the coefficient from the OLS is $0.8 \%$, while this coefficient is higher than $1 \%$ for all those above the median. Regarding the wage gap between men and women, the MCO indicated that men's wages are 5\% higher than women's.
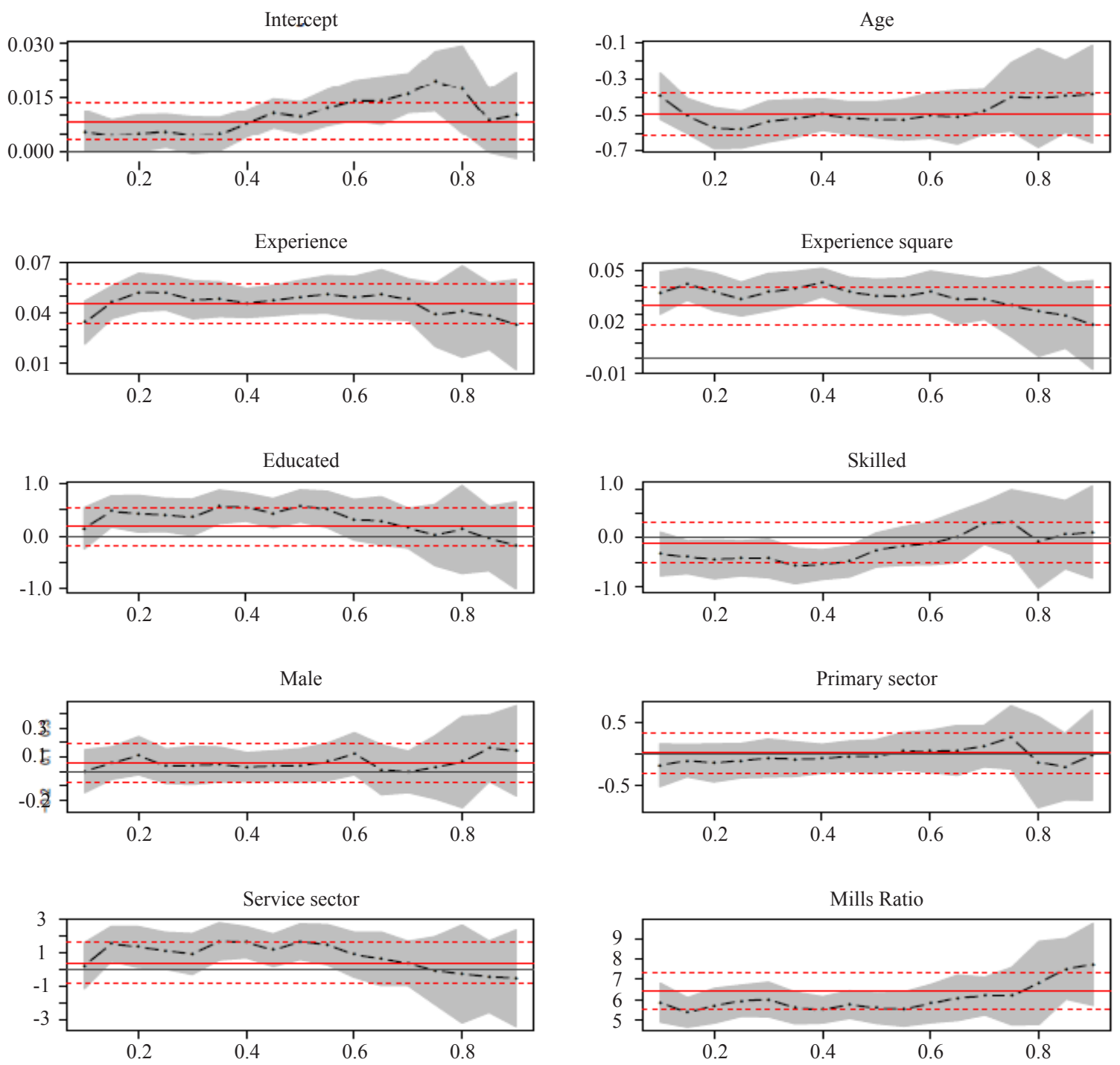

Figure 1. Estimated marginal effect on each quantile of wage estimated using the non-parametric quantile regression 
While this effect is less than 2.6\% for the first decile (MCO overestimated) against $14.8 \%$ for the last decile. Thus, the wage gap is smaller for low wages and very large for high wages. Figure 1-Estimation of coefficients by quantile regressions.

\subsection{Non linear quantile regression}

The previous results assumed a linear relation between individual characteristics and wage. In this section, we relax this hypothesis and estimated a nonlinear quantile model to predict wage rates. The results are presented in Figure 1. We find that the coefficients vary across the quantiles. However, the average effect remains close to the linear quantile regressions previously discussed

\subsection{Robustness check: decomposition of the wage gap}

\subsubsection{Discrimination between men and women}

Estimates have shown that the average wage for women is $5.3 \%$ lower than that of men. Of this $5.3 \%$, only a small part is explained by our explanatory variables, i.e. $0.2 \%$. The difference in the average gap represents the discrimination effect.

Figure 2 presents the sstimated contribution of variables on the gender gap. The sresults suggest that the observable characteristics of the employee i.e. age, experience, education level, etc. do not explain the gender pay gap. It would be more interesting to look at this difference from the point of view of the place of residence.

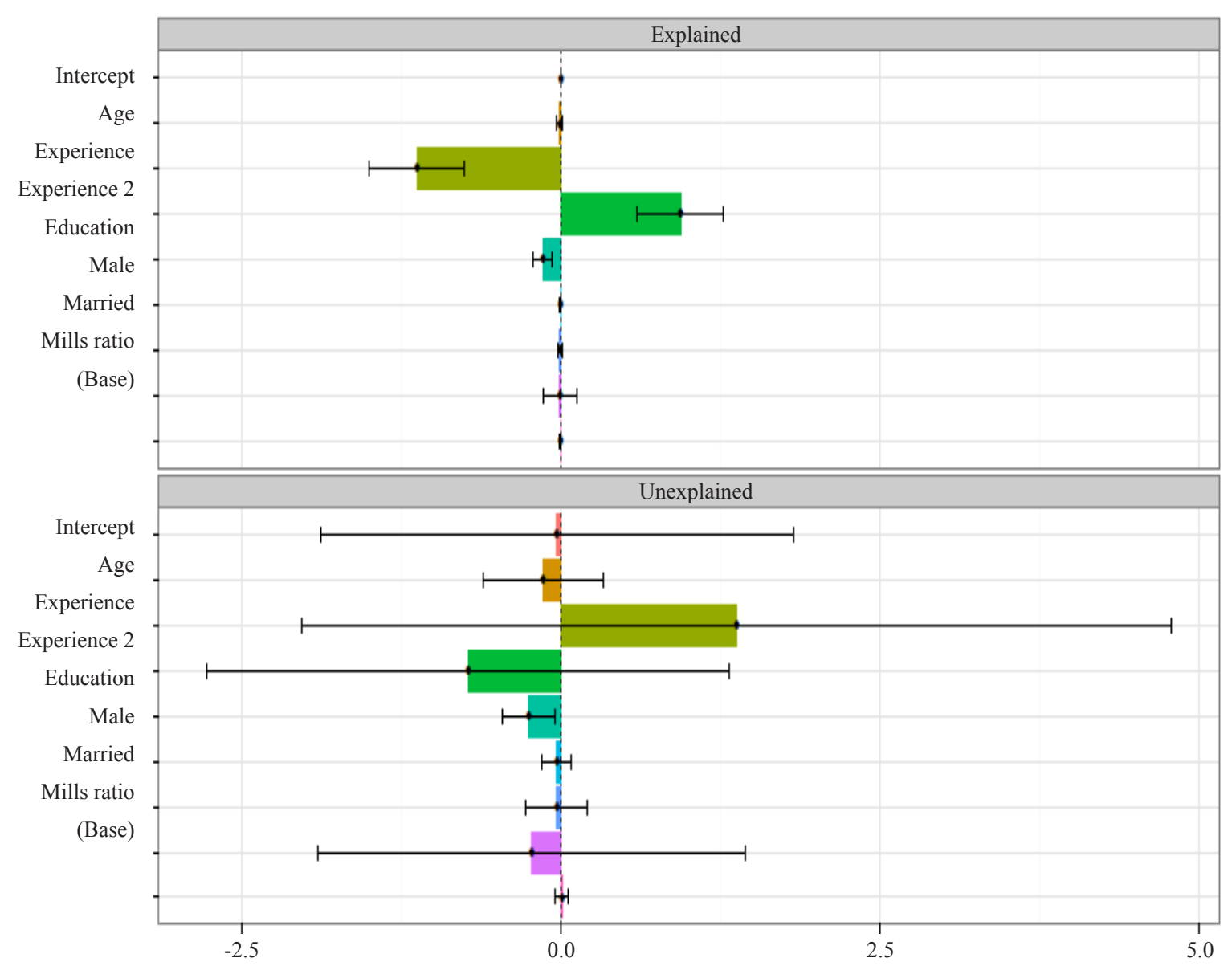

Figure 2. Estimated contribution of variables on the gender gap 


\subsubsection{Discrimination between qualified and unskilled workers}

For the level of qualification presented in Figure 3, we note that on average the salary of the qualified group is $40 \%$ higher than that of the unskilled group, of which $35 \%$ is explained by our explanatory variables. Thus, almost all this average gap between the qualified and the unskilled is explained by observable characteristics such as education, experience, etc.

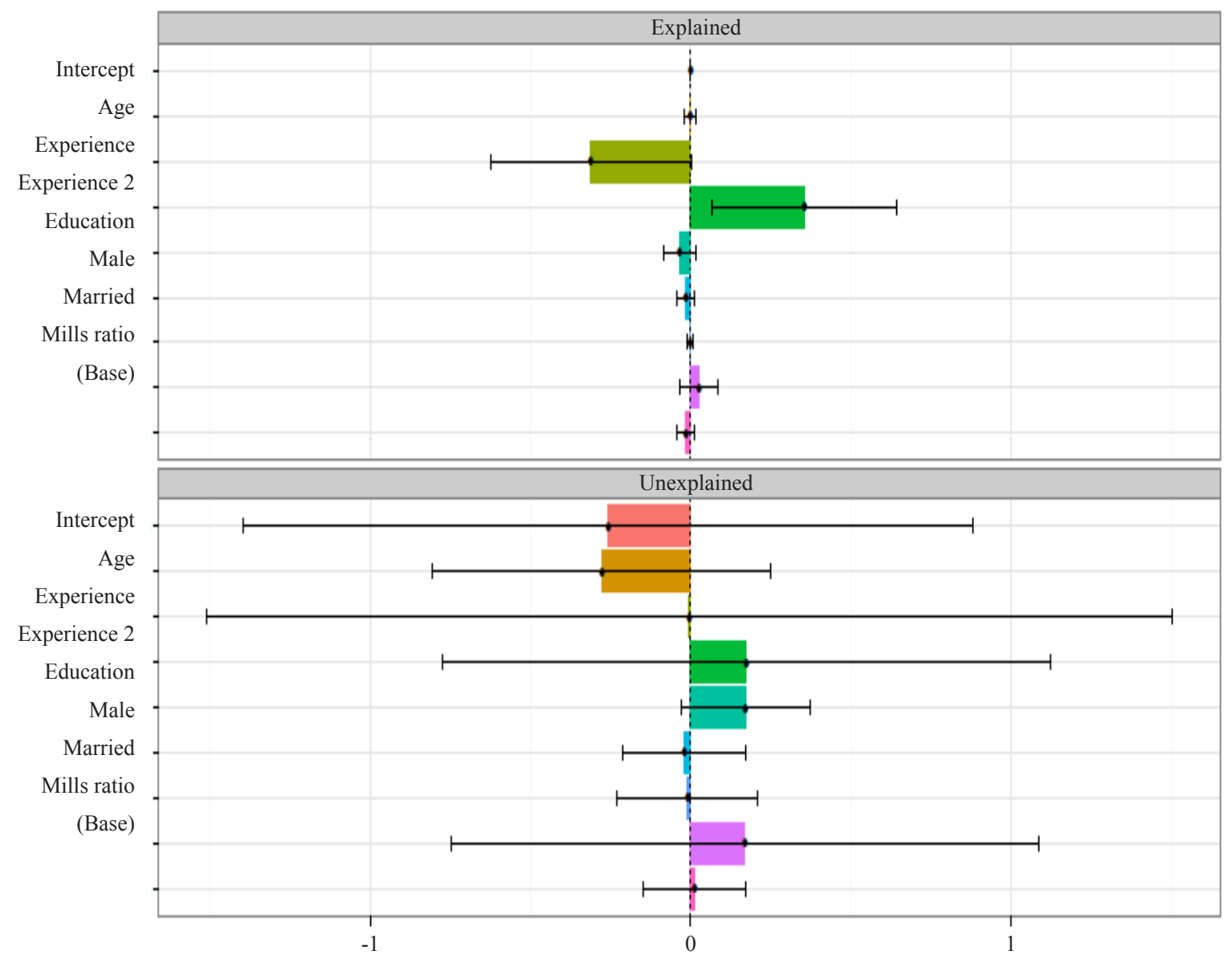

Figure 3. Estimated contribution of variables on the gap between skilled and unskilled

\section{Conclusion}

This study focused on estimating the determinates of wage inequality in West African countries. As labor compensation is not observed for non-workers and self-employed workers, the estimation is subject to selection bias. We used the two-stage sample selection model to correct this selection bias. The first stage allows to predict the probability of being a working female to account for the issue of sample selection bias. The second stage estimates the determinants of the wage rates. Subsequently, to consider the non-linear effect of individual characteristics on wages, we applied a quantile regression and a non-parametric estimation to access consistent effects.

Overall, the results suggest that education, experience, marital status, and gender are the major determinants of wages in west-African countries. The results also suggest that some wage differentials were not explained by education, experience, marital status, suggesting sex discrimination. Even though discrimination is now legally prohibited and socially condemned, this paper found evidence of wage discrimination in the labor in west African countries. These discriminatory practices have concrete consequences on the living and working conditions of employees, particularly on 
the level of wages.

This is one of the most complex problems for strategies to combat and prevent poverty. Because of the importance of work as a source of living, being deprived of or prevented from accessing it is one of the main causes of social and economic exclusion.

Moreover, integration policies in paid employment should be implemented to reduce this unequal wage distribution, especially for women and youth who remains largely discriminated in the labor market.

\section{References}

Adair, P., Bellache, Y., \& Gherbi, H. (2012). L'accès à l'emploi informel en Algérie: Déterminants et fonctions de gains, Inequalities and Development: new challenges, new measurements [Access to informal employment in Algeria: Determinants and earnings functions]. 4th Economic Development International Conference, University of Bordeaux.

Aeberhardt, R., Fougère, D., Pouget, J., \& Rathelot, R. (2007). L'emploi et les salaires des enfants d'immigrés. Economie et Statistique, 433-434, 31-46. https://doi.org/10.3406/estat.2010.8084

Amuedo-Dorantes, C. (2004). Determinants and poverty implications of informal sector work in Chile. Economic Development and Cultural Change, 52(2), 347-368.

Arbache, J. S., Kolzv, A., \& Filipiak, E. (2005). Gender Disparities in Africa's Labor Market. The World Bank.

Bassier, I., Budlender, J., Zizzamia, R., Leibbrandt, M., \& Ranchhod, V. (2021). Locked down and locked out: Repurposing social assistance as emergency relief to informal workers. World Development, 139, 105271. https:// doi.org/10.1016/j.worlddev.2020.105271

Becker, G. S. (1964). Human capital: A theoretical and empirical analysis, with special reference to education. First Edition, New York: National Bureau of Economic Research.

Belmondo, T. V. (2012). Discrimination salariale et équité gendorielle sur le marché du travail au Cameroun [Wage discrimination and gender equity in the labor market in Cameroon]. UN Women Working Paper, 3(20), 55-66.

Blinder, A. S. (1973). The board of regents of the university of wisconsin system wage discrimination: Reduced form and structural estimates. The Journal of Human Resources, 8(4), 436-455.

Boumahdi, R., \& Giret, J.-F. (2005). Une analyse économétrique des disparités d'accès à l'emploi et de rémunérations entre jeunes d'origine française et jeunes issus de l'immigration. Revue Économique, 56(3), 625. https://doi. org/10.3917/reco.563.0625

Buchinsky, M., Fougère, D., Kramarz, F., \& Tchernis, R. (2010). Interfirm mobility, wages and the returns to seniority and experience in the United States. Review of Economic Studies, 77(3), 972-1001. https://doi.org/10.1111/j.1467937X.2010.598.X

Cotton, J. (1988). On the decomposition of wage differentials. Journal of Econometrics, 61(1), 5-21. https://doi. org/10.1016/0304-4076(94)90074-4

Dienne, M., Dieng, S. A., Dramé, K., \& Fall, M. (2015). Analyse des determinants de la performance des entreprises en afrique subsaharienne francophone: Cas du Sénégal [Analysis of the Determinants of Firm Performance in Francophone Sub-Saharan Africa: The Case of Senegal]. International Development Research Center.

Heckman, J. (1974). Shadow prices, market wages, and labor supply. Econometrica, 42(4), 679-694. https://doi. org/10.2307/1913937

Heckman, J. J. (1979). Sample selection bias as a specification error. Econometrica, 47(1), 153-161. https://doi. org/10.2307/1912352

Hlavac, M. (2014). oaxaca: Blinder-Oaxaca Decomposition in R. R Package version 1.0.3. http://CRAN.R-Project.Org/ Package $=$ oaxaca, Jann 2008

ILO. (2019). Yearbooks for labour statistics. Geneva, Switzerland: International Labour Organization.

Jarrell, S. B., \& Stanley, T. D. (2004). Board of regents of the university of wisconsin system declining bias and gender wage discrimination? A meta-regression analysis declining bias and gender wage discrimination? The Journal of Human Resources, 39(3), 828-838.

King, A., \& Shackleton, C. M. (2021). Working in poverty: Informal employment of household gardeners in Eastern Cape towns, South Africa. Development Southern Africa. pp.1-14.

Manski, C. F., \& McFadden, D. (1981). Alternative estimators and sample designs for discrete choice analysis. Structural analysis of discrete data with econometric applications, 2, 2-50.

Mboup, S. D., Emini, C. A., Baldé, R., \& Diallo, T. M. (2016). L’impact des réformes commerciales sur l'emploi 
et le bien-être dans les pays de la CEDEAO: le cas du Sénégal. December [The Impact of Trade Reforms on Employment and Welfare in ECOWAS Countries: The Case of Senegal]. Working Paper No. 2016-26, Partnership for Economic Policy.

Mroz, T. (1987). The sensitivity of an empirical model of married women's hours of work to economic and statistical assumptions. The econometric society the sensitivity of an empirical model of married women's hours of work. Econometrica, 55(4), 765-799. https://doi.org/10.2307/1911029

Oaxaca, R. (1973). Economics department of the university of pennsylvania institute of social and economic researchosaka university. International Economic Review, 14(4), 693-709. http://www.jstor.org/stable/2527270

Reimers, C. W. (1983). Labor market discrimination against hispanic and black men. The Review of Economics and Statistics, 65(4), 570. https://doi.org/10.2307/1935925

Romain, A., Denis, F., Julien, P., \& Roland, R. (2010). Wages and employment of French workers with African origin. Journal of Population Economics, 23(3), 881-905. https://doi.org/10.1007/s00148-009-0266-3

Sall, A. C., \& Thiaw, M. (2019). Human capital, gender and the labor market in senegal human capital, gender and the labor market in Senegal. TIJ's Research Journal of Economics \& Business Studies-RJEBS, 8(9), 2251-1555. https:// academic.microsoft.com/paper/2955494008

Sarker, M. R. (2021). Labor market and unpaid works implications of COVID-19 for Bangladeshi women. Gender, Work \& Organization, 28(52), 597-604. https://doi.org/10.1111/gwao.12587

Thiaw, M. (2020). Politiques d'emp loi des jeunes et qualifications sur le marché du travail: cas du Sénégal [Youth employment policies and labor market skills: the case of Senegal]. Revue Africaine de Management, 5(3), $137-155$.

Weichselbaumer, D., \& Winter-Ebmer, R. (2005). A meta-analysis of the international gender wage gap. Journal of Economic Surveys, 19(3), 479-511. https://doi.org/10.1111/j.0950-0804.2005.00256.x 